\title{
Reply \#2 to Schimmack: Critique of Cesario et al. (2019)
}

\author{
Joseph Cesario \\ Michigan State University
}

Recently Cesario et al. (2019) published research in Social Psychological and Personality Science showing no antiBlack disparity in fatal police shootings when shootings were benchmarked against violent crime rates. In a formal critique submitted for publication to SPPS (available here) as well as on social media, Schimmack critiqued this work in a number of ways.

Here I show that Schimmack misunderstands and mischaracterizes the work of Cesario et al. (2019), so much so that his critique in no way changes the results or conclusions of the original study. I address each of his points in turn.

\section{Section I: "Distributing" Homicide vs. Non-Homicide Victims}

The most important criticism raised by Schimmack can be found on pages 11-12, specifically Table 3, of his critique. Here, Schimmack shows that the odds ratios can change by distributing victims of fatal police shootings in some proportion between those who were "homicide suspects" and those who were "not homicide suspects." Specifically, Table 3 shows that it is possible to classify enough victims of fatal police shootings as "non-homicide suspects" to make the odds ratios flip and show anti-Black disparity.

This is incorrect in two main ways. First, Schimmack has a persistent misunderstanding of the use of crime rates in our analyses. We are not classifying victims in terms of homicide suspects or not homicide suspects, despite his repeated insistence on approaching the question in this way. As stated in our paper and in emails to him, crime rates are used as proxies for exposure to deadly force situations, which is why we benchmark on 16 different measures of crime rather than just homicide rates. We do not claim that all victims (or even some victims) were homicide suspects at the times of their deaths, nor that police were investigating such victims as homicide suspects. As stated to Schimmack in an email dated 09/24/19, crime rates approximate the "likelihood that person from racial group $\mathrm{x}$ will be in a deadly-force relevant situation."

Putting that aside, however, Schimmack believes he has

Joseph Cesario is associate professor of psychology at Michigan State University. The original Cesario, Johnson, and Terrill (2019) manuscript and the Schimmack (2019) critique are available at the first author's website. discovered something new whereas in fact this point is already made in our paper. It is readily apparent in our original paper that not only did we recognize that odds ratios are variable and have uncertainty (e.g., in Tables 2 and 3) but we explicitly stated it multiple times. For instance, right in the abstract to our paper we wrote: "For unarmed shootings or misidentification shootings, data are too uncertain to be conclusive." That is, the data might be consistent with anti-White disparity, no disparity, or anti-Black disparity. At no point do we say that the shootings of unarmed citizens (which most closely match Schimmack's "non-homicide" classification) definitively show no anti-Black disparity. Instead, we say that the data are uncertain and therefore could be consistent with either anti-Black or anti-White disparity.

In a sentence that makes it seem like he is uncovering something novel and fundamentally damaging, Schimmack writes:

Once we change the assumptions, the conclusions can change and Cesario et al.'s data are entirely consistent with the hypothesis that police officers are more likely to use lethal force when they encounter a Black citizen.

This would be a damaging point if we had not already made this point explicitly in our abstract and throughout the paper. When considering unarmed and non-aggressing citizens, data are too uncertain and are consistent with anything from anti-White to anti-Black disparity. There is no ambiguity in our writing on this point.

Indeed, in an email dated 09/24/19 to Schimmack, I used his classification system to show that you could distribute the values in his Table 3 to produce anything from "virtually zero odds... to 3.7 odds in the anti-White direction."

Schimmack's sentences immediately following his Table 3 are telling: "I am not claiming that the scenario in Table 3 is realistic or true" and "To make an empirical contribution, the authors would need to examine the actual circumstances that led to a police shooting." Schimmack appears to have missed where this is discussed in the introduction and shown that the "actual circumstances" are those of violent crime, for nearly all police shootings. For those that do not fall under this circumstance, as we said the data are too uncertain to draw strong conclusions one way or the other.

Thus, Schimmack claims we should have done something that we actually did, thinks he has done something novel by 
creating a hypothetical world that produces anti-Black disparity, and then misses the fact that we stated that there was uncertainty surrounding such circumstances. What exactly his Table 3 contributes, then, remains unclear.

\section{Section II: A "Novel" Technique}

In what is perhaps the most puzzling of his criticisms, Schimmack repeatedly refers to our benchmarking approach as "novel." For example, he says "I show that these conclusions rest on a novel and flawed statistical approach," "based on their unscientific analyses of the data," and, from a 9/30/19 facebook post:

What is benchmarking.[sic] A new statistical approach invented by Cesario and Johnson to claim that there is no racial disparity in police shootings, when there are clear racial disparities in the population and among those who were unarmed or not a threat. Wow. How strong do you have to believe something to invent a whole statistical approach to support your beliefs? This is a true example of true ignorance.

While it would be exciting to have invented "a whole statistical approach," in fact nothing close to this is true. Even a cursory examination of research on policing demonstrates that the issue of benchmarking (and choosing a proper benchmark) has been discussed repeatedly within criminal justice and psychology since the 1970s (e.g., Fyfe, 1982, Goff, Lloyd, Geller, Raphael, \& Glaser, 2016, Inn, Wheeler, \& Sparling, 1977, Nix, Campbell, Byers, \& Alpert, 2017, Takagi, 1974). Benchmarking is an old, ubiquitous, and standard means of computing odds ratios that involves comparing some outcome to some standard. That's it. Consider the following examples:

- Are Black citizens more likely to get arrested for drug possession than White citizens? One might benchmark arrests against population levels (as Schimmack insists). Or, if drug use rates deviate from population rates, one might choose to benchmark arrests against rates of drug use.

- Are Black drivers more likely to get speeding tickets than White drivers? One might benchmark speeding tickets against population levels (as Schimmack insists). Or, if speeding varies between Blacks and Whites, one might choose to benchmark tickets against rates of speeding.

- Are Black citizens more likely to have physical force used against them by police officers than White citizens? One might benchmark use of force rates against population levels (as Schimmack insists). Or, if encounter rates differ between Blacks and Whites, one might choose to benchmark force rates against known rates of police encounters.

In all cases, benchmarking against one or another value is required. There is nothing novel or new about this. Moreover, it is not the case that any benchmark other than population levels will necessarily reduce the calculated racial disparity; indeed, it many cases other benchmarks will show greater anti-Black disparity.

To further show that this is not something we invented in order to get the outcome we wanted (as Schimmack claims above), I quote Dr. Phillip Atiba Goff (p. 16-17, Goff et al. 2016):

Population benchmarks provide only a crude method for estimating disproportionality. They allow for an inference that force is being used in a manner that is disproportionate to presence in the general population, but do not allow for a clear inference as to whether the force is disproportionate to presence in any particular area or to legitimately provocative behavior. A more direct, albeit still limited, proxy for level of provocative behavior would be actual offending. The closest available index of offending is arrest rates. While arrest rates are confounded by racial bias in policing practices, they provide a closer approximation than simple resident population.

Moreover, Dr. Goff's own analyses confirm what we claim: no anti-Black disparity (in fact, anti-White disparity) in fatal shootings when shooting rates are benchmarked on violent crime (Goff et al., 2016).

Thus, the claim that we invented a new statistical approach to find a particular result is clearly false. Unless Schimmack wants to claim that Dr. Goff also invented a new statistical approach in order to show no racial disparity and that Dr. Goff is also a true example of true ignorance, he should perhaps rethink the soundness of this argument in advance of future writings.

\section{Section III: A List of Various Inaccuracies in Schimmack's Commentary}

In order of severity:

- Schimmack says that it is our opinion that the deaths of unarmed civilians or those who die from initial discretionary contact with police "do not matter," based on the fact that we pointed out that this was a small number of cases. It is absolutely clear in the full context of the paragraph in which our statement appeared that we were solely referring to the impact of those cases on the analytic results and that we were not referring 
to the societal or interpersonal impact of those deaths. As we said, the small number of these cases "probably do not meaningfully impact the analyses." Of course these are tragic, horrible cases. No one disputes this.

- Schimmack presents an example using brown-eyed and blue-eyed citizens as a means of demonstrating why the benchmark of population proportion is appropriate. The example rests on a misunderstanding of fatal police shootings and a failure to appreciate the logic outlined in our introduction. He states (p. 7): "It is not clear what probabilities other than population proportions should be used." Crime rates are relevant probabilities, as we showed in our introduction, and the fact that such rates differ across races is the reason why crime rate benchmarks are appropriate.

- Schimmack claims that we were contradictory in (1) claiming that stereotypes cause officers to misidentify harmless objects while at the same time (2) showing no racial disparities in fatal shootings. He writes (p. 4):

Thus Cesario et al. (2019) contradict themselves when they claim that there are no racial disparities and that police officers are more likely to misidentify harmless objects as weapons when they encounter a Black citizen.

This is nonsensical. We used past research to set up a testable prediction and then showed that support for this prediction was not obtained. As we wrote:

Social psychological research suggests that race effects may be strongest under conditions of ambiguity (e.g., Duncan, 1976; Kunda \& Thagard, 1996), and experiments have shown robust race bias in weapon misidentification (at least for untrained civilians; Correll, Park, Judd, \& Wittenbrink, 2002; Payne, 2006). We therefore repeat the odds analyses restricting the data set to those unarmed citizens classified as reaching for or holding a harmless object at the time of shooting.

- Schimmack states (p. 4): "In fact, the authors later suggest that more contact with Black citizens could reduce racial bias. Thus, their speculations about the influence of exposure on stereotypes is contradictory." This demonstrates a mischaracterization of what we actually wrote, which is reproduced here in full:

One promising solution to this problem can be found in the social psychological literature on person perception and stereotyping.
This research has found strong effects of individuating information on people's judgments, and that clear individuating information reduces the influence of stereotypes with relative ease (see, e.g., Jussim, Cain, Crawford, Harber, \& Cohen, 2009; Kunda \& Thagard, 1996). Community policing and more "on the beat" officers may provide an opportunity for officers to gain individuating information about the public with whom they interact. Certainly, police officers cannot know every citizen in a neighborhood, but the likelihood of having individuating information about a given citizen is higher to the extent that police have had more contact with the public in non-crime contexts.

It is clear that we are talking about contact that results in individuating information about a citizen and the way this individuating information may reduce the reliance on stereotypes when interacting with that citizen. We were not, as Schimmack claims, saying that mere exposure to Black citizens will reduce racial bias.

- Schimmack again claims we were contradictory in our writing, stating (p. 5):

Once more, the authors contradict themselves. Here they claim that there is racial bias in shootings, while their main conclusion was that that [sic] "none of these tests provided evidence of systematic anti-Black disparity."

Again, this is a mischaracterization of our writing. In context, we had stated "We do caution the reader that the very small number of these cases translates to high uncertainty. However, if we assume this pattern remains as the data sets grow larger over the years, it may be instructive." In other words, when discussing potential racial disparity in unarmed shootings we had stated multiple times that the data were too uncertain to draw one conclusion or another. There is no contradiction to state that overall no evidence of anti-Black disparity was observed, while also stating that for certain subsets of shootings the data were too uncertain to draw firm conclusions.

- Schimmack states (p. 3): "...they provide no theoretical argument why high exposure to Black citizens or Black criminals causes police to shot [sic] and kill more Black civilians." This misses (1) the entire introduction where we document the context of violent crime surrounding fatal police shootings and (2) all our 
tests for disparities in shootings where violent crime is not likely.

- Schimmack states (p. 3):

Cesario et al.'s (2019) argument is that daily experiences of encountering Black citizens during investigations of criminal activities "reinforces associations between Black [sic] and criminals [sic]" (p. 592). This is pure speculation and ignores that police officers also encounter White criminals...

This is not our argument. We noted that the greater conditional probabilities of encountering Blacks in criminal contexts may undermine interventions such as implicit bias training. That indicators of criminal activity vary across racial groups is not in dispute. What is often disputed is the cause of these differences. We also at no point ignore the fact that Whites commit crime. (How would we even do such a thing? White crime rates are part of every analysis we conduct.)

- Schimmack states that we were incorrect in claiming that crime rates are difficult to change, when he states (p. 5): "The authors then make some unsubstantiated claims that it would be difficult to change racial differences in crime rates. However, decriminalizing minor drug possessions would not only reduce crime rates, it would also reduce racial disparities in crime rates." As we discussed at length in multiple places, minor drug possessions are not the type of crime at issue in fatal police shootings; violent crime rates are more relevant.

- Schimmack misrepresents our position when he states (p. 9): "The problem with this approach is that the authors implicitly assume that we can use the number of people killed in the population as a measure of the number of criminals that are being killed because police only shot [sic] and kill criminals." Nowhere do we state this. Again, Schimmack (1) is misunderstanding the use of crime rates as proxies of exposure to the police and (2) fails to remember that we divided up shooting types to address exactly this issue.

\section{Conclusion}

In sum, we showed that fatal police shootings benchmarked on crime rates fail to show the anti-Black disparity observed when benchmarked against population levels. We justified this through an analysis of the nature of fatal police shootings, which are overwhelmingly in the context of violent crime. We also note the high levels of uncertainty in shootings of unarmed civilians and of those civilians not aggressing against officers when shot. Nothing Schimmack wrote in his critique changes any of these conclusions.

\section{References}

Cesario, J., Johnson, D. J., \& Terrill, W. (2019). Is there evidence of racial disparity in police use of deadly force? Analyses of officer-involved fatal shootings in 2015-2016. Social Psychological Personality Science, 10, 586-595.

Fyfe, J. J. (1982). Blind justice: Police shootings in Memphis. J. Crim. L. Criminol., 73, 707-722.

Goff, P. A., Lloyd, T., Geller, A., Raphael, S., \& Glaser, J. (2016). The science of justice: Race, arrests, and police use offorce. Center for Policing Equity.

Inn, A., Wheeler, A. C., \& Sparling, C. L. (1977). The effects of suspect race and situation hazard on police officer shooting behavior. J. Appl. Soc. Psychol., 7(1), 27-37.

Nix, J., Campbell, B. A., Byers, E. H., \& Alpert, G. P. (2017). A bird's eye view of civilians killed by police in 2015: Further evidence of implicit bias. Criminology $\mathcal{E}$ Public Policy, 16(1), 309-340.

Schimmack, U. (2019). Presumed guilty until proven innocent: Benchmarking is not a valid statistical approach. Retrieved from https://replicationindex.com/2019/09/30/ benchmark-picking-is-not-a-valid-statistical -approach/ (Online; posted 09/30/2019)

Takagi, P. (1974). A garrison state in 'democratic' society. Crime Soc. Justice, 27-33. 